\title{
EDITORIAL
}

\section{Type 2 diabetes in Asia: where do we go from here?}

\author{
European Journal of Clinical Nutrition (2017) 71, 801-802; \\ doi:10.1038/ejen.2017.94
}

There is a global burden of type 2 diabetes (T2DM), and the predicted escalation in its prevalence will be acutely felt by India and China. It was timely to seek the opinions of the key researchers in these countries and from around the world, so we may benefit from their understanding of the developmental, environmental and lifestyle factors that are pertinent to the disease. This special issue took on the enormous task of covering the spectrum of nutrition and health-related research that informs the problem of T2DM in this region-from the epidemiology to clinical to cellular/molecular insights including some exciting future areas. The goal was to highlight what was known and what was emerging from different models of observation. Ultimately, by identifying overlapping areas of concern in this region and gaps in our understanding, a renewed effort in controlling the escalation of this disease could follow.

In this issue, several authors have ascribed the increased incidence of T2DM in Asia to rapid changes in lifestyle behaviours. $^{1-5}$ Increased intakes of refined carbohydrate (including sugars), greater saturated and less monounsaturated fat intake, low-quality protein, and decreased fruit and vegetable intake have combined with increased sedentariness and reductions in voluntary physical activity. Ambient air pollution including particulate matter is also a major concern in India and China. ${ }^{6}$ Air pollution will initiate and exacerbate a chronic inflammatory state that has effects on the growing foetus and the progression of adult disease. ${ }^{7,8}$ Coincident with these environmental and lifestyle changes has been a rapid increase in economic prosperity, unplanned urbanization, a new culture of fast food consumption, and a continued high prevalence of smoking and tuberculosis. ${ }^{6}$

The research of Krishnaveni and Yajnik ${ }^{9}$ reminds us that maternal nutritional status and metabolic state are equally important. Obesity and gestational diabetes influence birth outcome, and heavier babies have a greater risk of T2DM in adulthood. ${ }^{9,10}$ However, subtle changes to nutrient intake (vitamin B12, for example) can, through epigenetic pathways, imprint the growing foetus towards a phenotype that is 'thin but fat' even at birth. ${ }^{9}$ These are intergenerational effects. The recent emergence of an obesogenic environment in Asia would further modify the post-natal growth and metabolism of such babies, leading to the adult expression of the well-described 'Asian or Asian-Indian phenotype'. In an evolutionary perspective, Wells ${ }^{11}$ brings these facets together in a model that discusses the interaction of two traits, 'metabolic capacity' and 'metabolic load', and how variations in each may explain the risk of T2DM in this region.

There is promise that cellular models will further our understanding of the metabolic basis for the increased predisposition of Asians to T2DM. ${ }^{12}$ Uncontrolled T2DM, however, has multisystem manifestations that impose a huge financial cost to the individual and the nation. ${ }^{13}$ Perhaps we also need to study the cross-talk between other major organ systems and the $\beta$ cell, to better understand how best to control the disease. ${ }^{14}$ Such information could conceivably also lead to newer drug targets and functional food development. Systemic inflammation and immune function are closely linked to metabolic disease. ${ }^{15}$ Newer techniques now measure the bioenergetics of immune cells ${ }^{16}$ and this could prove very useful, if early disparities in such bioenergetic indices predicted future disease, or even signalled the normalization of metabolic dysfunction in response to treatment.

So where do we go from here? Do we need multisite, large-scale intervention trials targeting dietary and physical activity discrepancies common to these countries? Should there be a formal engagement between these countries at the highest level? And, do we place this issue at the top of our public health agenda? Gulati and Misra ${ }^{3}$ and Rhodes et al..$^{6}$ in this issue subscribe to lifestyle interventions for T2DM. There is some discussion on using the Prevención con Dieta Mediterránea (PREDIMED) trial as a template for the United States, and possibly as a multi-country intervention for T2DM. ${ }^{17}$ Increasing extra-virgin olive oil consumption and/or increased mixed nut intake were the key attributes of the PREDIMED success. ${ }^{18}$ Whether such recommendations suit the diet of Asians and their traditional culinary methods, would be important to investigate, since there is little information. ${ }^{19,20}$ However, there is also the view that 'movement is medicine'. Arena et al. $^{21}$ suggest a more personalized approach through technologydriven e-health/m-health platforms that could for instance, target a reduction in sedentarity.

Faced with the concomitant obesity epidemic, primary prevention (that is, a population approach built on a policy framework), as well as controlled and culturally adapted lifestyle interventions in at-risk groups (malnourished mothers, women with a history of gestational diabetes, individuals with prediabetes, and so on) are needed in a life course approach to reduce the prevalence of T2DM in Asia. ${ }^{22}$ Environmental health agencies in Asian countries would also have a major role in reducing air pollution. Moreover, the power of political influence, both at the national and international level, cannot be discounted. The success of smoking cessation was built around societal and political will among other measures, and supported by messages targeted at individuals. ${ }^{23}$ Political decisions to impose a tax on fat and sugar-sweetened beverages coupled with incentives for increasing fruit and vegetable intake, have been advocated for obesity and T2DM. ${ }^{3}$ Overall, the prevention of diabetes cannot reside within the health sector alone. Focusing on education, economic disparities, cultural diversity and human ecology would be important in formulating and sustaining a solution to this crisis. Perhaps, it is time we worked towards an integrated solution. ${ }^{24}$

\section{CONFLICT OF INTEREST}

The authors declare no conflict of interest.

M Soares ${ }^{1}$ and MJ Müller ${ }^{2}$

${ }^{7}$ Food Nutrition and Health, School of Public Health, Faculty of Health Sciences, Curtin University, Perth, Western Australia, Australia and ${ }^{2}$ Department of Human Nutrition and Food Science, ChristianAlbrechts-University of Kiel, Kiel, Germany E-mail: m.soares@curtin.edu.au

\section{REFERENCES}

1 Chavasit V, Kriengsinyos W, Photi J, Tontisirin K. Trends of increases in potential risk factors and prevalence rates of diabetes mellitus in Thailand. Eur J Clin Nutr 2017; 71: 839-843.

2 Deepa M, Anjana RM, Mohan V. Role of lifestyle factors in the epidemic of diabetes: lessons learnt from India. Eur J Clin Nutr 2017; 71: 825-831. 
3 Gulati S, Misra A. Abdominal obesity and type 2 diabetes in Asian Indians: dietary strategies including edible oils, cooking practices and sugar intake. Eur J Clin Nutr 2017; 71: 850-857.

4 Tee S-E, Yap RWK. Type 2 diabetes mellitus in Malaysia: current trends and risk factors. Eur J Clin Nutr 2017; 71: 844-849.

5 Zhang N, Du SM, Ma GS. Current lifestyle factors that increase risk of T2DM in China. Eur J Clin Nutr 2017; 71: 832-838.

6 Rhodes EJ, Gujral U, Venkat Narayan KM. Mysteries of type 2 diabetes: the Indian Elephant meets the Chinese Dragon. Eur J Clin Nutr 2017; 71: 805-811.

7 GBD 2013 Mortality and Causes of Death Collaborators. Global, regional, and national age-sex specific all-cause and cause-specific mortality for 240 causes of death, 1990-2013: a systematic analysis for the Global Burden of Disease Study 2013. Lancet 2015; 385: 117-171.

8 Wolf K, Popp A, Schneider A, Breitner S, Hampel R, Rathmann W et al. Association between long-term exposure to air pollution and biomarkers related to insulin resistance, subclinical inflammation and adipokines. Diabetes 2016; 65: 3314-3326.

9 Krishnaveni GV, Yajnik CS. Developmental origins of diabetes-an Indian perspective. Eur J Clin Nutr 2017; 71: 865-869.

10 Ma RCW, Tsoi KY, Tam WH, Wong CKC. Developmental origins of type 2 diabetes: a perspective from China. Eur J Clin Nutr 2017; 71: 870-880.

11 Wells JCK. Body composition and susceptibility to type 2 diabetes: an evolutionary perspective. Eur J Clin Nutr 2017; 71: 881-889.

12 Carlessi R, Keane KN, Mamotte C, Newsholme P. Nutrient regulation of $\beta$-cell function: what do islet cell/animal studies tell us? Eur J Clin Nutr 2017; 71: 890-895.

13 Pradeepa R, Mohan V. Prevalence of type 2 diabetes and its complications in India and economic costs to the nation. Eur J Clin Nutr 2017; 71: 816-824.
14 Shirakawa J, De Jesus DF, Kulkarni RN. Exploring inter-organ crosstalk to uncover mechanisms that regulate $\beta$-cell function and mass. Eur J Clin Nutr 2017; 896-903.

15 Hotamisligil GS. Inflammation and metabolic disorders. Nature 2006; 444: 860-867.

16 Keane KN, Calton EK, Carlessi R, Hart PH, Newsholme P. The bioenergetics of inflammation: insights into obesity and type 2 diabetes. Eur J Clin Nutr 2017; 71: 904-912.

17 American Society of Nutrition. Prospects for a US/multi-country replication of PREDIMED. Scientific Session Experimental Biology meeting, 2017. Available at: https://asnsscientificsessionsatexp2017.sched.com/event/9m7Y/prospects-fora-us-multi-country-replication-of-predimed.

18 Appel $L$, van Horn L. Did the PREDIMED trial test a Mediterranean diet? N Engl J Med 2013; 368: 1353-1354.

19 Nigam P, Bhatt S, Misra A, Chada DS, Vaidya M, Dasgupta J et al. Effect of a 6-month intervention with cooking oils containing a high concentration of monounsaturated fatty acids (olive and canola oils) in male Asian Indians with non-alcoholic fatty liver disease compared with refined oil. Diabetes Technol Ther 2014; 16: 255-261.

20 Calton EK, James AP, Pannu PK, Soares MJ. Certain dietary patterns are beneficial for the metabolic syndrome: reviewing the evidence. Nutr Res 2014; 34: 559-568.

21 Arena R, Sagner M, Byrne NM, Williams AD, McNeil A, Street SJ et al. Novel approaches for the promotion of physical activity and exercise for prevention and management of type 2 diabetes. Eur J Clin Nutr 2017; 71: 858-864.

22 Darton-Hill I, Nishida C, James WPT. A life course approach to diet, nutrition and the prevention of chronic diseases. Public Health Nutr 2004; 71A: 101-121.

23 World Health Organization (WHO). Framework convention on tobacco control. WHO Document Production Services. Geneva: Switzerland.

24 Frenk J, Gomez-Dantes O. False dichotomies in global health: the need for integrative thinking. Lancet 2017; 389: 667-670. 